\title{
Correction to: Fused Deposition Modeling of Poly (lactic acid)/ Nutshells Composite Filaments: Effect of Alkali Treatment
}

\author{
Xiaohui Song ${ }^{1,2}\left(\mathbb{D} \cdot\right.$ Wei $\mathrm{He}^{1} \cdot{\text { Xingguo } \mathrm{Han}^{2} \cdot \text { Huadong Qin }}^{2}$
}

Published online: 5 September 2020

○) Springer Science+Business Media, LLC, part of Springer Nature 2020

\section{Correction to: \\ Journal of Polymers and the Environment (2020) https://doi.org/10.1007/s10924-020-01839-z}

The article Fused Deposition Modeling of Poly (lactic acid)/ Nutshells Composite Filaments: Effect of Alkali Treatment, written by Xiaohui Song, Wei He, Xingguo Han, Huadong Qin was originally published electronically on the publisher's internet portal (currently SpringerLink) on 29 July 2020 with open access.

With the author(s)' decision to step back from Open Choice, the copyright of the article changed on 4 September 2020 to (C) Springer Science+Business Media, LLC, part of Springer Nature 2019 and the article is forthwith distributed under the terms of copyright
Publisher's Note Springer Nature remains neutral with regard to jurisdictional claims in published maps and institutional affiliations.

The original article can be found online at https://doi.org/10.1007/ s10924-020-01839-z.

Wei He

wei_he@gxu.edu.cn

1 Present Address: College of Chemistry \& Chemical Engineering, Guangxi Key Laboratory of Processing for Non-ferrous Metallic and Featured Materials, Guangxi University, Nanning, China

2 College of Mechanical Engineering, Guilin University of Aerospace Technology, Guilin, China 